\title{
REMOÇÃO DE MATÉRIA ORGÂNICA, DE NUTRIENTES E DE COLIFORMES NO PROCESSO ANAERÓBIO EM DOIS ESTÁGIOS (REATOR COMPARTIMENTADO SEGUIDO DE REATOR UASB) PARA O TRATAMENTO DE ÁGUAS RESIDUÁRIAS DE SUINOCULTURA ${ }^{1}$
}

\author{
MÁRIO S. DE ABREU NETO ${ }^{2}$, ROBERTO A. DE OLIVEIRA ${ }^{3}$
}

RESUMO: Neste trabalho, avaliou-se o efeito das águas residuárias de suinocultura, com concentrações médias de sólidos suspensos totais variando de 4.591 a $13.001 \mathrm{mg} \mathrm{L}^{-1}$, no desempenho de processo anaeróbio, em dois estágios, compostos por reator compartimentado (ABR) e reator de fluxo ascendente com manta de lodo (UASB), instalados em série, em escala- -piloto (volumes de 530 e $120 \mathrm{~L}$, respectivamente), submetidos a tempos de detenção hidráulica (TDH) de 60; 36 e $24 \mathrm{~h}$ no primeiro reator, e de 13,6; 8,2 e 5,4 h no segundo reator. As eficiências médias de remoção de $\mathrm{DQO}_{\text {total }}$ variaram de 69 a $84 \%$ no reator ABR e de 39 a $58 \%$ no reator UASB, resultando em valores médios de 87 a $94 \%$ para o sistema de tratamento anaeróbio em dois estágios, com carga orgânica volumétrica (COV) na faixa de 11,5 a 18,0 $\mathrm{g} \mathrm{DQO}_{\text {total }}(\mathrm{L} \mathrm{d})^{-1}$ no reator ABR, e de 4,2 a 13,4 $\mathrm{g} \mathrm{DQO}_{\text {total }}(\mathrm{L} \mathrm{d})^{-1}$ no reator UASB. A produção volumétrica máxima de metano de $0,227 \mathrm{~m}^{3} \mathrm{CH}_{4}\left(\mathrm{~m}^{3} \text { reator } \mathrm{d}\right)^{-1}$ ocorreu no reator UASB, com COV de 10,6 $\mathrm{g} \mathrm{DQO}_{\text {total }}(\mathrm{L} \mathrm{d})^{-1}$ e TDH de 5,4 h. As maiores eficiências de remoção de coliformes totais e termotolerantes $(99,7 \%)$, DQO diss $(94 \%)$, SST (96\%), NTK (71\%), P-total $(61 \%)$ e outros nutrientes, no sistema de tratamento anaeróbio em dois estágios, foram obtidas com o TDH de 73,6 h e temperatura climatológica média de $24,6{ }^{\circ} \mathrm{C}$, aplicando-se a menor $\mathrm{COV}\left(\mathrm{de} 11,5 \mathrm{~g} \mathrm{DQO}_{\text {total }}(\mathrm{L} \mathrm{d})^{-1}\right.$ no reator $\mathrm{ABR}$, e de 4,2 $\mathrm{g} \mathrm{DQO}_{\text {total }}(\mathrm{L} \mathrm{d})^{-1}$ no reator UASB) com a maior concentração de SST do afluente (13.001 $\left.\mathrm{mg} \mathrm{L}^{-1}\right)$.

PALAVRAS-CHAVE: carga orgânica volumétrica, digestão anaeróbia, reator anaeróbio de chicanas, resíduos de suínos, remoção de metais.

\section{ORGANIC MATTER, NUTRIENTS AND COLIFORMS REMOVAL IN A TWO-STAGE ANAEROBIC PROCESS (ANAEROBIC BAFFLED REACTOR FOLLOWED BY UASB REACTOR) FOR SWINE WASTEWATER TREATMENT}

ABSTRACT: In this work it was evaluated the effect of swine wastewater with mean total suspended solid (TSS) concentration ranging from 4.591 to $13.001 \mathrm{mg} \mathrm{L}^{-1}$ on the performance of the anaerobic process in two stages composed of anaerobic baffled reactors (ABR) and an upflow sludge blanket reactor (UASB), installed in series, in pilot scale testing (volumes of 530 and $120 \mathrm{~L}$, respectively) and with hydraulic detention times (HDT) of 60; 36 and $24 \mathrm{~h}$ in the ABR reactor and 13.6; 8.2 and $5.4 \mathrm{~h}$ in the UASB reactor. The mean $\mathrm{COD}_{\text {total }}$ removal efficiency varied from 69 to $84 \%$ in the ABR reactor and from 39 to $58 \%$ in the UASB reactor, resulting in average values ranging from 87 to $94 \%$ for the twostage anaerobic treatment system under organic loading rate (OLR) of 11.5 to $18.0 \mathrm{~g}$ total COD (L d) ${ }^{-1}$ in the ABR reactor and 4.2 to $13.4 \mathrm{~g}$ total $\mathrm{COD}(\mathrm{L} \mathrm{d})^{-1}$ in the UASB reactor. The maximum volumetric methane production of $0.227 \mathrm{~m}^{3} \mathrm{CH}_{4}\left(\mathrm{~m}^{3} \text { reactor } \mathrm{d}\right)^{-1}$ occurred in the UASB reactor with OLR of $10.6 \mathrm{~g}$ total COD $(\mathrm{L} \mathrm{d})^{-1}$ and HDT of $5.4 \mathrm{~h}$. The most removal efficiencies of thermotolerant coliforms (99.7), diss COD (94\%), TSS (96\%), NTK (71\%), P-total (61\%) and other minerals in the two-stage anaerobic treatment system was obtained with HDT of $73.6 \mathrm{~h}$ and medium air temperature of $24.6^{\circ} \mathrm{C}$, applying the minor OLR of $11.5 \mathrm{~g}$ total COD $(\mathrm{L} \mathrm{d})^{-1}$ in the ABR reactor and $4.2 \mathrm{~g}$ total COD $(\mathrm{L} \mathrm{d})^{-1}$ in the UASB reactor with the biggest affluent TSS $\left(13.001 \mathrm{mg} \mathrm{L}^{-1}\right)$.

KEYWORDS: organic loading rate, anaerobic digestion, anaerobic baffled reactor, swine waste, metal removal.

\footnotetext{
${ }^{1}$ Extraído da dissertação de Mestrado do primeiro autor. Trabalho financiado pela FAPESP.

${ }^{2}$ Biólogo, Mestre em Microbiologia Agropecuária, Departamento de Engenharia Rural, UNESP, Jaboticabal - SP, Fone: (0XX16) 3209.2637, mariosaneto@yahoo.com.br

${ }^{3}$ Eng $^{\mathrm{o}}$ Agrônomo e Tecnólogo em Construção Civil, Mestre em Agronomia - Produção Vegetal, Doutor em Engenharia Civil Hidráulica e Saneamento, Prof. Doutor, Departamento de Engenharia Rural, UNESP, Jaboticabal - SP, Fone: (0XX16) 3209.2637, raoder@fcav.unesp.br

Recebido pelo Conselho Editorial em: 16-10-2007
}

Aprovado pelo Conselho Editorial em: 18-2-2009 


\section{INTRODUÇÃO}

O crescimento da população mundial e o consequente aumento do consumo per capita de alimentos provocaram mudanças na estrutura dos sistemas de produção, e a tradicional agricultura familiar caracterizada pela criação de pequeno número de animais foi sendo substituída por um sistema tecnificado com capacidade de produzir grande quantidade de proteína animal em reduzido espaço físico, provocando o acúmulo de dejetos que, armazenados e manejados inadequadamente, comprometem irreversivelmente a qualidade do ar, da água e do solo.

As águas residuárias de suinocultura, caracterizadas por altas concentrações de sólidos suspensos (em torno de $80 \%$ dos 0,1 a $3 \%$ de sólidos totais), DQO, N e P, têm alto poder poluidor (OLIVEIRA, 1997). Disposto de forma inadequada, esse resíduo gera sérios problemas ambientais ligados à depleção do oxigênio dissolvido, eutrofização, quantidades excessivas de nitrato em águas superficiais e subterrâneas, toxicidade por amônia a peixes e problemas de saúde em virtude da presença de microrganismos patogênicos (FERNANDES \& OLIVEIRA, 2006). A digestão anaeróbia pode ser aplicada como alternativa no tratamento desses resíduos para a redução do poder poluente e, ao mesmo tempo, terá aplicação direta de seus subprodutos (biogás e efluente estabilizado) na propriedade rural. CHERNICHARO (2007) ainda citou como vantagens do tratamento anaeróbio, baixo consumo de energia, baixa produção de lodo, baixa demanda de área, dentre outras.

O reator anaeróbio compartimentado ou de chicanas (Anaerobic Baffled Reactor - ABR) é um tanque com diversas câmaras dispostas horizontalmente em série, cada qual separada por paredes ou chicanas verticais, através das quais o líquido se movimenta descendente e ascendentemente ao longo do reator, permitindo que a água residuária atravesse regiões de elevada concentração de microrganismos ativos que se formam junto ao fundo do reator (BARBER \& STUCKEY, 1999). Segundo VOSSOUGHI et al. (2003), o reator de chicanas combina as vantagens do filtro anaeróbio, que apresenta alta estabilidade e segurança, e do reator UASB, no qual a própria biomassa agregada facilita a sua retenção no reator. NACHAIYASIT \& STUCKEY (1997) ressaltaram a estabilidade do reator quando submetido a variações bruscas de carga orgânica.

O reator UASB consiste em um tanque, no fundo do qual se localiza o digestor, e no topo um decantador precedido por um sistema de separação de gases. Devido as suas características hidrodinâmicas, construtivas e operacionais, tem sido cada vez mais utilizado, apresentando elevadas eficiências tratando águas residuárias predominantemente solúveis, mas, assim como outros reatores anaeróbios de alta taxa, apresenta limitações para o tratamento de águas residuárias com altas concentrações de sólidos suspensos, em virtude das dificuldades relacionadas à hidrólise desses sólidos orgânicos. Por isso, seria vantajosa a adoção do processo anaeróbio em dois estágios, que consiste em dois reatores instalados em série, sendo o primeiro para a hidrólise parcial da matéria orgânica particulada e o segundo para digerir os compostos solúveis formados no primeiro reator (HAANDEL \& LETTINGA, 1994).

FERNANDES (2004), utilizando reator compartimentado (ABR) seguido de reator UASB no processo anaeróbio em dois estágios, tratando águas residuárias de suinocultura com concentrações em torno de $6.000 \mathrm{mg} \mathrm{L}^{-1}$, com $\mathrm{TDH}$ de 18 a $56 \mathrm{~h}$ no primeiro reator, obteve produções volumétricas de metano de até $0,755 \mathrm{~m}^{3} \mathrm{CH}_{4}\left(\mathrm{~m}^{3}\right.$ reator d) ${ }^{-1}$ e eficiências de remoção no sistema de tratamento (ABR+UASB) de DQO, SST e coliformes fecais de até 95; 96 e 99,99\%, respectivamente.

Diante dos resultados promissores obtidos com esse sistema de tratamento, da sua potencialidade também para a remoção de nutrientes, e tendo em vista que, em granjas com manejo dos resíduos de suínos em lâmina d'água, as concentrações de sólidos suspensos totais (SST) nos dejetos brutos são da ordem de $10.000 \mathrm{mg} \mathrm{L}^{-1}$, pretendeu-se, neste trabalho, avaliar a produção de metano e as remoções de DQO, de sólidos, de nutrientes e de coliformes no processo anaeróbio, em dois estágios (reator compartimentado seguido de reator UASB), no tratamento de águas residuárias de suinocultura com concentrações de SST do afluente de 4.591 a $13.001 \mathrm{mg} \mathrm{L}^{-1}$, aplicando-se tempo de detenção hidráulica (TDH) de 60; 36 e 24 h no reator compartimentado. 


\section{MATERIAL E MÉTODOS}

A pesquisa foi realizada nas instalações experimentais e nos laboratórios de Biodigestão Anaeróbia do Departamento de Engenharia Rural, da Faculdade de Ciências Agrárias e Veterinárias, da Universidade Estadual Paulista - UNESP, Câmpus de Jaboticabal. O sistema de tratamento foi constituído por dois reatores anaeróbios (compartimentado com três câmaras (ABR) e UASB)) em escala-piloto, instalados em série, com volumes de $530 \mathrm{~L}$ (primeiro estágio - ABR) e 120 L (segundo estágio - UASB), conforme descrito por FERNANDES \& OLIVEIRA (2006). Apresenta, também, caixas para armazenamento do afluente e bomba helicoidal para a alimentação do reator ABR, conforme ilustrado na Figura 1. Para o monitoramento da produção de biogás, foram instalados selos hidráulicos e gasômetros (FERNANDES \& OLIVEIRA, 2006).

Para a alimentação do sistema de tratamento, foi utilizado dejeto bruto de suínos confinados em fase de terminação, manejados com uso de lâmina d'água, na granja da UNESP-Jaboticabal, alimentados com ração à base de milho e soja, com complementos vitamínico e mineral. $\mathrm{O}$ dejeto foi pré-peneirado (peneira com malha quadrada de abertura de $3 \mathrm{~mm}$ ) para a separação dos sólidos particulados que pudessem entupir a linha de alimentação do reator.

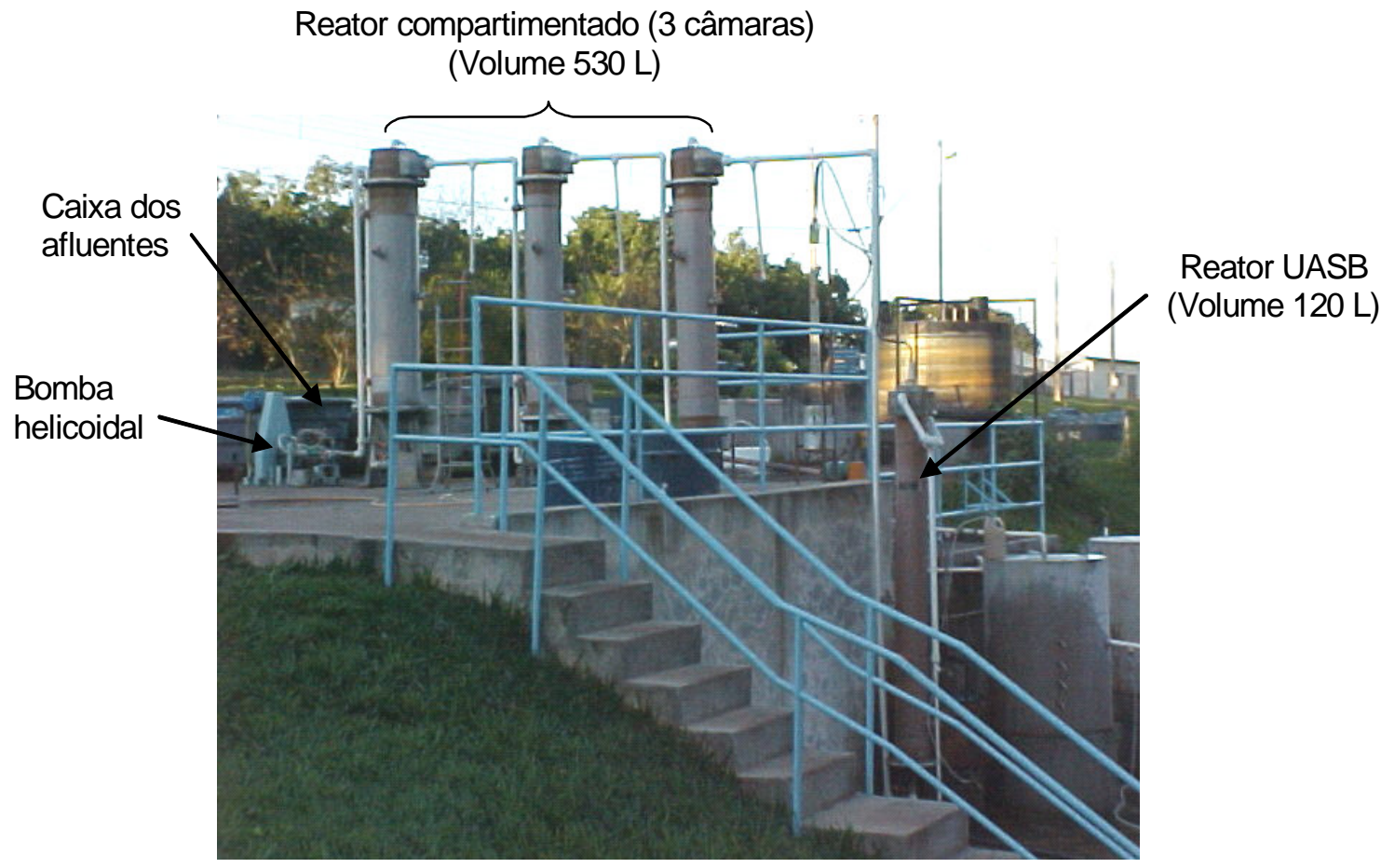

FIGURA 1. Instalações experimentais compostas por reator compartimentado (ABR) seguido de reator UASB. Fonte: FERNANDES \& OLIVEIRA (2006). Experimental facilities consisted of anaerobic baffled reactor (ABR) followed by UASB reactor. Source: FERNANDES \& OLIVEIRA (2006).

$\mathrm{Na}$ Tabela 1, estão apresentadas as condições operacionais dos ensaios 1; 2 e 3 do experimento com o sistema de tratamento com os reatores, compartimentado (ABR) e UASB.

Para a partida do sistema, foi utilizado lodo, com ST de $20,0 \mathrm{~g} \mathrm{~L}^{-1}$ e SV de $15,0 \mathrm{~g} \mathrm{~L}^{-1}$, proveniente de reatores UASB, tratando águas residuárias de suinocultura, e foi adicionado em quantidade suficiente para ocupar 20 a $30 \%$ do volume de cada câmara do reator anaeróbio compartimentado (ABR) e do reator UASB. No início dos ensaios 2 e 3, foram mantidos os mesmos 20 a 30\% do volume de cada reator preenchido com lodo.

Foram coletadas amostras na tubulação de entrada do sistema (afluente), nas tubulações de saída das três câmaras do reator compartimentado (ABR) e na saída do reator UASB (efluentes). As 
amostras $(2 \mathrm{~L})$ foram compostas por subamostras $(400 \mathrm{~mL})$ coletadas a cada hora, no período das 8 às $12 \mathrm{~h}$, e mantidas em geladeira $\left(\mathrm{a} 4^{\circ} \mathrm{C}\right)$ até a utilização para os exames e determinações analíticas no laboratório.

TABELA 1. Condições operacionais do sistema de tratamento anaeróbio em dois estágios (reator compartimentado (ABR) seguido de reator UASB) para os ensaios 1; 2 e 3. Operational conditions of two-stage anaerobic treatment system (anaerobic baffled reactor (ABR) followed by UASB reactor) for tests 1; 2 and 3.

\begin{tabular}{ccccccc}
\hline \multirow{2}{*}{ Ensaios } & Duração (dias) & $\begin{array}{c}\text { RDH } \\
(\mathrm{h})\end{array}$ & $\begin{array}{c}\mathrm{SST}^{-1} \\
\left(\mathrm{mg} \mathrm{L}^{-1}\right)\end{array}$ & $\begin{array}{c}\mathrm{DQO} \\
\left(\mathrm{mg} \mathrm{L}^{-1}\right)\end{array}$ & $\begin{array}{c}\mathrm{COV} \\
\left(\mathrm{g} \mathrm{DQO}\left(\mathrm{L} \mathrm{d}^{-1}\right)\right.\end{array}$ & $\begin{array}{c}\text { TDH } \\
(\mathrm{h})\end{array}$ \\
\hline 1 & 51 & 60 & 13.001 & 28.770 & 11,5 & 13,6 \\
2 & 54 & 36 & 11.866 & 26.971 & 18,0 & 8,2 \\
3 & 52 & 24 & 4.591 & 13.350 & 13,4 & 5,4 \\
\hline
\end{tabular}

TDH - tempo de detenção hidráulica; SST - sólidos suspensos totais; DQO - demanda química de oxigênio; COV carga orgânica volumétrica.

Nessas amostras, foram feitas determinações de $\mathrm{DQO}_{\text {total }}$, $\mathrm{DQO}_{\text {diss }}, \mathrm{DQO}_{\mathrm{ss}}$, SST e SSV duas vezes por semana, de acordo com APHA/ AWWA/ WPCF (1998) e OLIVEIRA (1997). O volume do biogás produzido foi monitorado diariamente, por meio de medidas em gasômetros, como descrito por OLIVEIRA (1997), e a composição do biogás foi analisada semanalmente, em cromatografia gasosa, conforme descrito por APHA/ AWWA/ WPCF (1998).

As medidas de alcalinidade parcial (AP), alcalinidade total (AT) e $\mathrm{pH}$ foram efetuadas diariamente, segundo metodologias descritas por APHA/AWWA/WPCF (1998), JENKINS et al. (1983), e os ácidos voláteis totais (AVT) foram determinados duas vezes por semana, conforme descrito por DILALLO \& ALBERTSON (1961). Foram ainda realizadas, uma vez por semana, determinações de N-total Kjeldahl (NTK), N-amoniacal e N-orgânico, P-total, K, Ca, Mg, Cu, Fe, $\mathrm{Na}, \mathrm{Mn}$ e Zn, conforme descrito por APHA/AWWA/WPCF (1998). O número mais provável (NMP) de coliformes totais e de termotolerantes foi avaliado duas vezes por ensaio, por meio da técnica de tubos múltiplos, descrita pela APHA/AWWA/WPCF (1998). As temperaturas médias do ar foram obtidas na Estação Agroclimatológica do Departamento de Ciências Exatas da UNESP, Câmpus de Jaboticabal.

Foi realizada análise estatística dos valores obtidos por meio dos testes $\mathrm{F}$ e de Tukey, considerando-se o delineamento inteiramente casualizado, com três tratamentos (TDH de 60; 36 e $24 \mathrm{~h}$ ) e com sete repetições, para os macro e micronutrientes; 14 repetições para DQO, sólidos suspensos, ácidos voláteis, e 30 repetições para $\mathrm{pH}$, alcalinidade total e parcial, e produção de metano. As repetições foram provenientes das amostragens durante os ensaios, considerando-se as condições de estabilidade dos reatores, em virtude de os valores dos coeficientes de variação (C.V.) das eficiências de remoção de $\mathrm{DQO}_{\text {total }}$ e sólidos suspensos (SS) do sistema de tratamento anaeróbio, em dois estágios (ABR+UASB), nos ensaios, terem sido menores que $10 \%$.

\section{RESULTADOS E DISCUSSÃO}

$\mathrm{Na}$ Tabela 2, observa-se que, para a temperatura média do ar e COV aplicadas nos reatores ABR e UASB, ocorreram diferenças significativas com as menores temperaturas, coincidindo com as maiores COV aplicadas no ensaio 2. Os valores da $\mathrm{DQO}_{\text {total }}, \mathrm{DQO}_{\mathrm{ss}}, \mathrm{SST}, \mathrm{SSV}$, alcalinidade total (AT), ácidos voláteis totais (AVT), NTK, P-total, $\mathrm{Ca}, \mathrm{Fe}$ e $\mathrm{Mn}$ no afluente diferiram significativamente, com as menores médias no ensaio 3 (Tabelas 2 e 4). 
TABELA 2. Valores médios e coeficiente de variação (C.V.) da temperatura média do ar; das cargas orgânicas volumétricas (COV) aplicadas nos reatores ABR e UASB; de pH, da alcalinidade total (AT), da alcalinidade parcial (AP), dos ácidos voláteis totais (AVT), da demanda química de oxigênio total $\left(\mathrm{DQO}_{\text {total }}\right)$, da demanda química de oxigênio dissolvida $\left(\mathrm{DQO}_{\text {diss }}\right)$, da demanda química de oxigênio devido aos sólidos suspensos $\left(\mathrm{DQO}_{\mathrm{ss}}\right)$, dos sólidos suspensos totais (SST) e dos sólidos suspensos voláteis (SSV), nos afluentes e efluentes dos reatores ABR e UASB, e a produção volumétrica de metano nos reatores ABR, UASB e sistema de tratamento anaeróbio em dois estágios (ABR+UASB), nos ensaios 1;2 e 3. Mean values and variation coefficient (CV) of mean air temperature; organic loading rate (OLR) applied in the ABR and UASB reactors; $\mathbf{p H}$, total alkalinity (TA), partial alkalinity (PA), total volatile acids (TVA), total chemical oxygen demand $\left(\mathrm{COD}_{\text {total }}\right)$, dissolved chemical oxygen demand $\left(\mathrm{DQO}_{\text {diss }}\right)$, chemical oxygen demand due to suspended solids $\left(\mathrm{DQO}_{\mathrm{ss}}\right)$, total suspended solids (TSS) and volatile suspended solids (VSS) in the affluents and effluents of ABR and UASB reactors, and the volumetric methane production in ABR and UASB reactors and twostage anaerobic treatment system (ABR + UASB) in tests $1 ; 2$ and 3.

\begin{tabular}{|c|c|c|c|c|c|c|}
\hline \multirow{2}{*}{ Parâmetros } & \multirow{2}{*}{ Reator/Amostra } & \multicolumn{3}{|c|}{ Ensaio } & \multirow{2}{*}{ C.V. (\%) } & \multirow{2}{*}{ Teste F } \\
\hline & & 1 & 2 & 3 & & \\
\hline Temperatura $\left({ }^{\circ} \mathrm{C}\right)$ & - & $24,6 \mathrm{a}$ & $22,8 \mathrm{~b}$ & $24,2 \mathrm{a}$ & 7,6 & $14,75 * *$ \\
\hline \multirow{2}{*}{$\mathrm{TDH}(\mathrm{h})$} & ABR & 60 & 36 & 24 & - & - \\
\hline & UASB & 13,6 & 8,2 & 5,4 & - & - \\
\hline \multirow{2}{*}{$\begin{array}{c}\mathrm{COV} \\
\left(\mathrm{g} \mathrm{DQO}_{\text {total }}(\mathrm{L} \mathrm{d})^{-1}\right.\end{array}$} & $\mathrm{ABR}$ & $11,51 \mathrm{~b}$ & $17,98 \mathrm{a}$ & $13,40 \mathrm{ab}$ & 46,8 & $3,49 *$ \\
\hline & UASB & $4,21 \mathrm{~b}$ & $13,29 \mathrm{a}$ & $10,58 \mathrm{a}$ & 58,7 & $10,07 * *$ \\
\hline \multirow{3}{*}{$\mathrm{pH}$} & Afluente & $6,16 a$ & $6,31 \mathrm{a}$ & $6,21 \mathrm{a}$ & 5,4 & $1,45 \mathrm{~ns}$ \\
\hline & $\mathrm{ABR}$ & $7,30 \mathrm{a}$ & $7,25 \mathrm{a}$ & $6,99 \mathrm{~b}$ & 3,6 & $12,03 * *$ \\
\hline & UASB & $7,54 \mathrm{a}$ & $7,36 \mathrm{~b}$ & $7,07 \mathrm{c}$ & 2,9 & $36,09 * *$ \\
\hline \multirow{3}{*}{$\begin{array}{c}\mathrm{AT} \\
\left(\mathrm{mg} \mathrm{CaCO}_{3} \mathrm{~L}^{-1}\right)\end{array}$} & Afluente & $1.638 \mathrm{a}$ & $1.118 \mathrm{~b}$ & $778 \mathrm{c}$ & 42,2 & $22,77 * *$ \\
\hline & ABR & $1.485 \mathrm{a}$ & $1.293 \mathrm{a}$ & $923 \mathrm{~b}$ & 36,5 & $12,07 * *$ \\
\hline & UASB & $1.434 \mathrm{a}$ & $1.315 \mathrm{a}$ & $891 \mathrm{~b}$ & 36,6 & $12,35 * *$ \\
\hline \multirow{3}{*}{$\begin{array}{c}\mathrm{AP} \\
\left(\mathrm{mg} \mathrm{CaCO}_{3} \mathrm{~L}^{-1}\right)\end{array}$} & Afluente & $397 a$ & $212 b$ & $186 \mathrm{~b}$ & 52,5 & $18,56 * *$ \\
\hline & $\mathrm{ABR}$ & $1.134 \mathrm{a}$ & $800 \mathrm{~b}$ & $579 c$ & 43,6 & $18,37 * *$ \\
\hline & UASB & $1.138 \mathrm{a}$ & $880 \mathrm{~b}$ & $592 \mathrm{c}$ & 40,9 & $18,52 * *$ \\
\hline \multirow{3}{*}{$\begin{array}{c}\mathrm{AVT} \\
\left(\mathrm{mg} \mathrm{CH}_{3} \mathrm{COOH} \mathrm{L} \mathrm{L}^{-1}\right)\end{array}$} & Afluente & $1.309 \mathrm{a}$ & $1.044 \mathrm{ab}$ & $721 \mathrm{~b}$ & 36,8 & $8,55 * *$ \\
\hline & ABR & $181 \mathrm{~b}$ & $351 \mathrm{a}$ & $209 a b$ & 67,4 & $4,18 *$ \\
\hline & UASB & $145 \mathrm{~b}$ & $276 a$ & $179 a b$ & 61,4 & $4,33 *$ \\
\hline \multirow{3}{*}{$\begin{array}{l}\mathrm{DQO}_{\text {total }} \\
\left(\mathrm{mg} \mathrm{L}^{-1}\right)\end{array}$} & Afluente & $28.770 \mathrm{a}$ & $26.971 \mathrm{a}$ & $13.350 \mathrm{~b}$ & 43,3 & 10,03 ** \\
\hline & ABR & $2.402 \mathrm{~b}$ & $4.518 \mathrm{a}$ & $2.434 \mathrm{~b}$ & 55,4 & $6,91 * *$ \\
\hline & UASB & $1.362 \mathrm{~b}$ & $3.324 \mathrm{a}$ & $1.491 \mathrm{~b}$ & 74,2 & $7,22 * *$ \\
\hline \multirow{3}{*}{$\begin{array}{l}\mathrm{DQO}_{\text {diss }} \\
\left(\mathrm{mg} \mathrm{L}^{-1}\right)\end{array}$} & Afluente & $4.055 \mathrm{a}$ & $2.816 \mathrm{~b}$ & $2.548 \mathrm{~b}$ & 42,7 & $5,04 *$ \\
\hline & ABR & $386 \mathrm{~b}$ & $992 \mathrm{a}$ & $561 \mathrm{ab}$ & 89,5 & $4,08 *$ \\
\hline & UASB & $253 \mathrm{~b}$ & $704 \mathrm{a}$ & $432 \mathrm{ab}$ & 88,2 & $4,33 *$ \\
\hline \multirow{3}{*}{$\begin{array}{l}\mathrm{DQO}_{\mathrm{ss}} \\
\left(\mathrm{mg} \mathrm{L}^{-1}\right)\end{array}$} & Afluente & $24.714 \mathrm{a}$ & $24.155 \mathrm{a}$ & $10.802 \mathrm{~b}$ & 49,0 & $9,12 * *$ \\
\hline & $\mathrm{ABR}$ & $2.016 \mathrm{~b}$ & $3.525 \mathrm{a}$ & $1.873 \mathrm{~b}$ & 55,1 & $6,33 * *$ \\
\hline & UASB & $1.109 \mathrm{~b}$ & $2.620 \mathrm{a}$ & $1.059 \mathrm{~b}$ & 83,9 & $6,15 * *$ \\
\hline \multirow{3}{*}{$\begin{array}{c}\mathrm{SST} \\
\left(\mathrm{mg} \mathrm{L}^{-1}\right)\end{array}$} & Afluente & $13.001 \mathrm{a}$ & $11.865 \mathrm{a}$ & $4.591 \mathrm{~b}$ & 51,3 & $11,49 * *$ \\
\hline & $\mathrm{ABR}$ & $1.126 \mathrm{~b}$ & $1.879 \mathrm{a}$ & $730 \mathrm{~b}$ & 48,5 & $13,10 * *$ \\
\hline & UASB & $649 \mathrm{~b}$ & $1.462 \mathrm{a}$ & $439 \mathrm{~b}$ & 86,5 & $7,52 * *$ \\
\hline \multirow{3}{*}{$\begin{array}{c}\mathrm{SSV} \\
\left(\mathrm{mg} \mathrm{L}^{-1}\right)\end{array}$} & Afluente & $10.717 \mathrm{a}$ & $9.691 \mathrm{a}$ & $3.339 \mathrm{~b}$ & 53,4 & $12,51 * *$ \\
\hline & $\mathrm{ABR}$ & $820 \mathrm{~b}$ & $1.443 \mathrm{a}$ & $529 \mathrm{~b}$ & 47,2 & $15,83 * *$ \\
\hline & UASB & $481 \mathrm{~b}$ & $1.070 \mathrm{a}$ & $334 \mathrm{~b}$ & 84,3 & $7,58 * *$ \\
\hline \multirow{3}{*}{$\begin{array}{c}\text { Prod. volumétrica de } \\
\text { metano } \\
\left(\mathrm{m}^{3} \mathrm{CH}_{4}\left(\mathrm{~m}^{3} \text { reator } \mathrm{d}\right)^{-1}\right)\end{array}$} & ABR & $0,144 \mathrm{a}$ & $0,154 \mathrm{a}$ & $0,065 \mathrm{~b}$ & 49,5 & $21,10 * *$ \\
\hline & UASB & $0,076 \mathrm{~b}$ & $0,201 \mathrm{a}$ & $0,227 \mathrm{a}$ & 49,4 & $30,39 * *$ \\
\hline & Sistema & $0,130 \mathrm{~b}$ & $0,163 \mathrm{a}$ & $0,094 \mathrm{c}$ & 40,3 & $14,03 * *$ \\
\hline
\end{tabular}

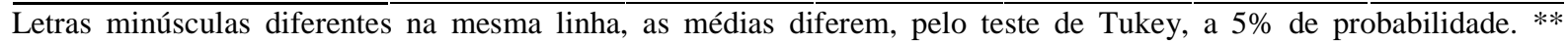
significativo a $1 \%$ de probabilidade; * significativo a $5 \%$ de probabilidade; ns - não significativo. 
Observou-se que os valores de $\mathrm{pH}$, em todas as fases de operação, sofreram variações crescentes a partir da entrada do afluente até a saída do sistema de tratamento. Segundo LETTINGA (1995), a maioria dos sistemas de tratamento anaeróbio é operada na faixa de $\mathrm{pH}$ entre 6,5 e 7,5, recomendando-se a manutenção de $\mathrm{pH}$ maior do que 6,2. Baixos valores de $\mathrm{pH}$ estão geralmente relacionados a altas concentrações de ácidos graxos voláteis e, consequentemente, à falência do processo.

Os valores médios de $\mathrm{pH}$ do afluente variaram de 6,16 a 6,31 e aumentaram para 6,99 a 7,30 no efluente do reator ABR, e para 7,07 a 7,54 na saída do reator UASB, como consequência da remoção de ácidos graxos voláteis (AVT) e aumento da alcalinidade de bicarbonatos (AP) na total (AT). A alcalinidade parcial está relacionada à presença de íons bicarbonato, responsáveis pelo tamponamento do sistema no valor de $\mathrm{pH}$ desejado para as atividades biológicas; a alcalinidade total, por sua vez, correlaciona todos os compostos capazes de neutralizar ácidos, incluindo-se, entre outros, os íons carbonatos, os bicarbonatos e os ácidos orgânicos voláteis (SILVA \& NOUR, 2005).

Os valores de $\mathrm{pH}$ e de AT nos efluentes decresceram significativamente $(\mathrm{P}<0,01)$ com a diminuição do TDH, contudo houve influência dos menores valores de AT nos afluentes. CHERNICHARO (2007) ressaltou que o pH, a alcalinidade e a concentração de AVT são parâmetros intimamente relacionados e de igual importância para o controle e para a operação adequada de reatores anaeróbios. No ensaio 1, observou-se decréscimo nos valores de AT nos efluentes dos reatores ABR e UASB; já nos ensaios 2 e 3, notou-se acréscimo nos valores médios de AT. Verificou-se que, em todos os ensaios, houve diminuição acentuada no valor da concentração de AVT do afluente ao longo do sistema de tratamento com os reatores ABR e UASB (Tabela 2), em virtude da transformação desses em biogás pelas arqueas metanogênicas.

Os valores médios de AVT nos efluentes dos reatores ABR e UASB, no $1^{0}$ ensaio, foram de 181 e $145 \mathrm{mg} \mathrm{L}^{-1}$, e diferiram significativamente $(\mathrm{P}<0,05)$ do $2^{-}$ensaio, em que os valores médios foram de 351 e $276 \mathrm{mg} \mathrm{L}^{-1}$, respectivamente. No ensaio 3, os valores médios de 209 e $179 \mathrm{mg} \mathrm{L}^{-1}$ mantiveram-se similares $(\mathrm{P}>0,05)$ aos obtidos nos dois primeiros ensaios. Esses valores e variações do $\mathrm{pH}$, dos AVT e da AT indicaram condições de estabilidade durante a operação dos reatores nos ensaios 1; 2 e 3 com aumento da alcalinidade de bicarbonato (AP) na AT, melhorando a capacidade de tamponamento dos reatores e não permitindo o acúmulo de ácidos graxos voláteis.

Os valores médios da $\mathrm{DQO}_{\text {total }}$ do afluente nos três ensaios foram de $28.770 \mathrm{mg} \mathrm{L}^{-1}$, $26.971 \mathrm{mg} \mathrm{L}^{-1}$ e $13.350 \mathrm{mg} \mathrm{L}^{-1}$, respectivamente, diminuindo ao longo do reator ABR e no reator UASB. Os valores médios da $\mathrm{DQO}_{\text {total }}$, no $2^{\mathrm{o}}$ ensaio, de 4.518 e $3.324 \mathrm{mg} \mathrm{L}^{-1}$, nos efluentes dos reatores $\mathrm{ABR}$ e UASB, respectivamente, foram significativamente maiores $(\mathrm{P}<0,01)$ do que os observados no $1^{-}$e $3^{-0}$ ensaios. Comportamento similar foi observado para os valores de $\mathrm{DQO}_{\text {diss }}$,

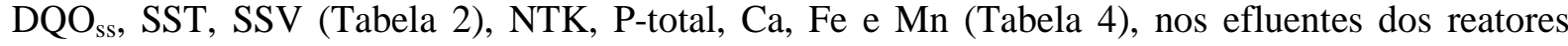
ABR e UASB.

Essas diferenças de desempenho entre os ensaios 1 e 2 foram provocadas pelas maiores COV aplicadas durante o ensaio 2, com a diminuição do TDH de $60 \mathrm{~h}$ para $36 \mathrm{~h}$, coincidindo com a ocorrência das menores temperaturas. No ensaio 3, a $\mathrm{DQO}_{\text {total }}$ do afluente diminuiu significativamente $(\mathrm{P}<0,01)$, a temperatura aumentou para valores semelhantes aos do ensaio 1 , e mesmo com o menor TDH (24 h) não houve aumento significativo $(\mathrm{P}>0,05)$ da COV, de tal forma que os valores de $\mathrm{COV}$ e da temperatura foram semelhantes aos observados no ensaio 1. Isso indicou que, para a manutenção da qualidade do efluente, os parâmetros mais importantes foram a COV e a temperatura do ar.

LANGENHOFF \& STUCKEY (2000), trabalhando com reator ABR (10 L e oito compartimentos), tratando água residuária com DQO de $500 \mathrm{mg} \mathrm{L}^{-1}$ e com TDH de $10 \mathrm{~h}$, obtiveram remoções de DQO de 95\%, 70\% e $60 \%$, com temperaturas de $35{ }^{\circ} \mathrm{C}, 20{ }^{\circ} \mathrm{C}$ e $10{ }^{\circ} \mathrm{C}$, respectivamente, verificando, assim, que acréscimos na temperatura são acompanhados por aumentos da eficiência de remoção de DQO. 
Os valores médios da $\mathrm{DQO}_{\mathrm{ss}}$ no afluente, resultante da diferença entre $\mathrm{DQO}_{\text {total }}$ e $\mathrm{DQO}_{\text {diss }}$, corresponderam, na média, a 86; 90 e $81 \%$ da DQO $_{\text {total }}$ do afluente do reator ABR nos ensaios 1; 2 e 3, respectivamente. Esses resultados são similares aos obtidos por OLIVEIRA (1997), SANTANA \& OLIVEIRA (2005) e FERNANDES \& OLIVEIRA (2006), os quais, em trabalhos realizados com águas residuárias de suinocultura, obtiveram $\mathrm{DQO}_{\mathrm{ss}}$ entre 66 e $80 \% ; 71,0$ e 76,5\% e 66,1 e 73,6\% da $\mathrm{DQO}_{\text {total }}$ do afluente, respectivamente. Os valores médios da $\mathrm{DQO}_{\mathrm{ss}}$ no efluente do reator $\mathrm{ABR}$ e no efluente do reator UASB corresponderam, na média, a $84 ; 78$ e $77 \%$, e a $81 ; 79$ e $71 \%$ da $\mathrm{DQO}_{\text {total }}$, nos ensaios 1; 2 e 3, respectivamente.

Os valores médios de $\mathrm{DQO}_{\mathrm{ss}}$ nos efluentes seguiram o mesmo padrão da $\mathrm{DQO}_{\text {total }}$, com o $2^{\underline{\mathrm{o}}}$ ensaio diferindo significativamente $(\mathrm{P}<0,05)$ dos demais.

No reator ABR, operado com valores de COV de 11,51 a 17,98 g DQO total $(\mathrm{L} \mathrm{d})^{-1}$ (Tabela 2), foram obtidas eficiências de remoção de $\mathrm{DQO}_{\text {total }}$ predominantemente acima de $65 \%$ (Figura 2) e não houve diferença significativa $(\mathrm{P}>0,05)$ para os valores médios (de 69 a $84 \%)$ entre os ensaios (Tabela 3). As eficiências de remoção de $\mathrm{DQO}_{\text {diss }}$ e $\mathrm{DQO}_{\mathrm{ss}}$, as quais variaram, na média, de 44 a $78 \%$ e de 74 a $89 \%$, respectivamente, diferiram significativamente $(\mathrm{P}<0,01)$, com os maiores valores ocorrendo no ensaio 1 (Tabela 3 ).

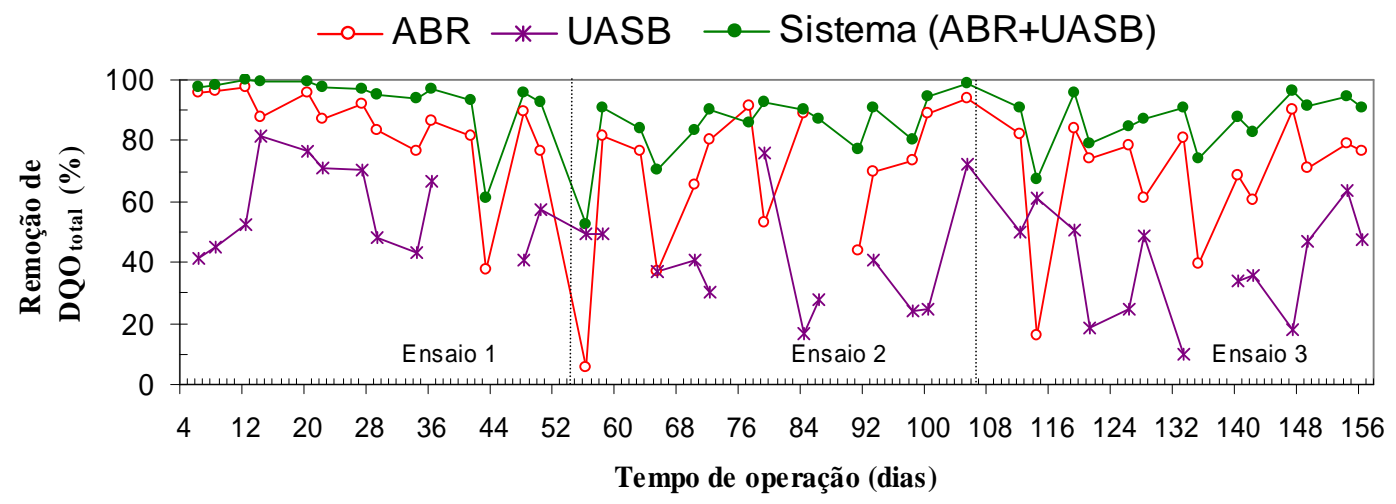

FIGURA 2. Eficiência de remoção de $\mathrm{DQO}_{\text {total, }}$ nos reatores $\mathrm{ABR}$ e UASB e no sistema de tratamento anaeróbio, em dois estágios (ABR+UASB), durante os ensaios 1;2 e 3. Removal efficiency of $\mathrm{COD}_{\text {total }}$ in $\mathrm{ABR}$ and UASB reactors and in the twostage anaerobic treatment system (ABR+UASB), during tests 1, 2 and 3.

No reator UASB, com COV aplicadas de 4,21; 13,29 e 10,58 g DQO total $(\mathrm{L} \mathrm{d})^{-1}$, os valores médios de eficiência de remoção de $\mathrm{DQO}_{\text {total }}$ foram de 58; 40 e 39\% (Tabela 3), nos ensaios 1; 2 e 3 , respectivamente, e diferiram significativamente $(\mathrm{P}<0,05)$. Apesar das menores eficiências, houve importante contribuição do reator 2 para que o sistema de tratamento (ABR+UASB) atingisse até 94\% de eficiência de remoção com estabilidade (C.V. $<10 \%$ ) no ensaio 1, não diferindo significativamente $(\mathrm{P}>0,05)$ dos $87 \%$ obtidos nos ensaios 2 e 3 . Para a $\mathrm{DQO}_{\text {diss, }}$, as eficiências de remoção no segundo reator foram, para os ensaios 1; 2 e 3, de 36; 28 e 25\%, respectivamente, e não diferiram significativamente $(\mathrm{P}>0,05)$ (Tabela 3). Contudo, as maiores eficiências de remoção de DQO $_{\text {diss }}$ no reator ABR mantiveram o desempenho superior do sistema de tratamento $(\mathrm{ABR}+\mathrm{UASB})$ no $1^{\mathrm{o}}$ ensaio, diferindo significativamente $(\mathrm{P}<0,05)$ do $2^{\underline{0}}$ e do $3^{\underline{0}}$ ensaios, indicando a maior influência do TDH também na remoção de fração dissolvida da matéria orgânica.

Os valores médios de eficiência de remoção de $\mathrm{DQO}_{\mathrm{ss}}$ no reator $\mathrm{ABR}$, de $89 ; 76$ e $74 \%$, foram maiores do que no reator UASB, de 62; 42 e 47\%, nos ensaios 1; 2 e 3, respectivamente, e diferiram significativamente $(\mathrm{P}<0,05)$ (Tabela 3). Apesar disso, para o sistema de tratamento (ABR+UASB), não houve diferença entre os ensaios $(\mathrm{P}>0,05)$. 
TABELA 3. Valores médios e coeficientes de variação (C.V.) das eficiências de remoção (\%) da demanda química de oxigênio total $\left(\mathrm{DQO}_{\mathrm{total}}\right)$, da demanda química de oxigênio dissolvida $\left(\mathrm{DQO}_{\text {diss }}\right)$, da demanda química de oxigênio devido aos sólidos suspensos $\left(\mathrm{DQO}_{\mathrm{ss}}\right)$, dos sólidos suspensos totais (SST) e dos sólidos suspensos voláteis (SSV) nos reatores ABR, UASB e sistema tratamento anaeróbio em dois estágios $(A B R+U A S B)$ nos ensaios 1; 2 e 3 . Mean values and variation coefficients (CV) of the removal efficiencies $(\%)$ of total chemical oxygen demand $\left(\mathrm{COD}_{\text {total }}\right)$, dissolved chemical oxygen demand $\left(\mathrm{COD}_{\text {diss }}\right)$, chemical oxygen demand due to suspended solids $\left(\mathrm{COD}_{\mathrm{ss}}\right)$, total suspended solids (TSS) and volatile suspended solids (VSS) in ABR and UASB reactors and two-stage anaerobic treatment system (ABR + UASB) in tests 1, 2 and 3.

\begin{tabular}{|c|c|c|c|c|c|c|}
\hline \multirow{2}{*}{ Parâmetros } & \multirow{2}{*}{ Reator } & \multicolumn{3}{|c|}{ Ensaio } & \multirow{2}{*}{ C.V. $(\%)$} & \multirow{2}{*}{ Teste F } \\
\hline & & 1 & 2 & 3 & & \\
\hline \multirow{3}{*}{$\mathrm{DQO}_{\text {total }}$} & $\mathrm{ABR}$ & $84 \mathrm{a}$ & $72 \mathrm{a}$ & $69 a$ & 23,7 & $2,97 \mathrm{~ns}$ \\
\hline & UASB & $58 \mathrm{a}$ & $40 \mathrm{~b}$ & $39 \mathrm{~b}$ & 37,4 & $4,67 *$ \\
\hline & Sistema & $94 \mathrm{a}$ & $87 \mathrm{a}$ & $87 \mathrm{a}$ & 9,65 & $3,41 *$ \\
\hline \multirow{3}{*}{$\mathrm{DQO}_{\text {diss }}$} & ABR & $78 \mathrm{a}$ & $44 \mathrm{c}$ & $62 \mathrm{~b}$ & 26,7 & $13,71 * *$ \\
\hline & UASB & $36 a$ & $28 \mathrm{a}$ & $25 \mathrm{a}$ & 47,9 & $2,07 \mathrm{~ns}$ \\
\hline & Sistema & $94 \mathrm{a}$ & $76 \mathrm{~b}$ & $83 \mathrm{~b}$ & 13,7 & $8,78 * *$ \\
\hline \multirow{3}{*}{$\mathrm{DQO}_{\mathrm{ss}}$} & ABR & $89 a$ & $76 \mathrm{ab}$ & $74 \mathrm{~b}$ & 18,8 & $3,98 *$ \\
\hline & UASB & $62 \mathrm{a}$ & $42 \mathrm{~b}$ & $47 \mathrm{ab}$ & 39,0 & $3,35 *$ \\
\hline & Sistema & $92 \mathrm{a}$ & $88 \mathrm{a}$ & $85 a$ & 16,5 & $0,98 \mathrm{~ns}$ \\
\hline \multirow{3}{*}{ SST } & ABR & $92 \mathrm{a}$ & $79 \mathrm{~b}$ & $83 a b$ & 11,9 & $5,73 * *$ \\
\hline & UASB & $61 \mathrm{a}$ & $40 \mathrm{~b}$ & $41 \mathrm{~b}$ & 38,8 & $5,09 *$ \\
\hline & Sistema & $96 a$ & $86 \mathrm{~b}$ & $87 \mathrm{~b}$ & 8,53 & $7,29 * *$ \\
\hline \multirow{3}{*}{ SSV } & ABR & $93 \mathrm{a}$ & $81 \mathrm{~b}$ & $82 \mathrm{~b}$ & 11,8 & $5,81 * *$ \\
\hline & UASB & $61 \mathrm{a}$ & $42 \mathrm{~b}$ & $41 \mathrm{~b}$ & 38,3 & $4,86 *$ \\
\hline & Sistema & $97 \mathrm{a}$ & $88 \mathrm{~b}$ & $86 \mathrm{~b}$ & 8,05 & $7,77 * *$ \\
\hline
\end{tabular}

Letras minúsculas diferentes na mesma linha, as médias diferem, pelo teste de Tukey, a 5\% de probabilidade. ** - significativo a $1 \%$ de probabilidade; $*$ - significativo a $5 \%$ de probabilidade; ns - não significativo.

Os valores médios das concentrações de SST no afluente foram de $13.001 ; 11.865$ e de $4.591 \mathrm{mg} \mathrm{L}^{-1}$ (Tabela 2) nos ensaios 1; 2 e 3, respectivamente, e diferiram estatisticamente $(\mathrm{P}<0,01)$. Essa diferença deveu-se a variações pronunciadas nos valores de SST no ensaio 3, provocadas por alterações no manejo da água e no número e na idade dos animais por baia, na granja de suínos. Nos efluentes dos reatores ABR e UASB, os valores médios de SST diminuíram para $1.126 ; 1.879$ e $730 \mathrm{mg} \mathrm{L}^{-1}$, e $649 ; 1.462$ e $439 \mathrm{mg} \mathrm{L}^{-1}$, respectivamente. No 2o ensaio, os valores foram maiores e diferiram significativamente $(\mathrm{P}<0,01)$ em relação aos dos ensaios 1 e 3 , para os reatores ABR e UASB.

As eficiências médias de remoção de SST e SSV, no sistema de tratamento anaeróbio, em dois estágios, com os reatores ABR e UASB, foram altas nos ensaios 1; 2 e 3, com valores médios de 96 e $97 \%$, 86 e $88 \%$ e 87 e $86 \%$, respectivamente (Tabela 3). Destaca-se o $1^{\circ}$ ensaio, no qual se obtiveram as maiores eficiências $(\mathrm{P}<0,05)$, em virtude do maior $\mathrm{TDH}$ associado a menores produções de biogás, facilitando a remoção física dos sólidos suspensos por sedimentação. Embora no segundo reator tenham ocorrido menores remoções de matéria orgânica, houve contribuição para a elevação da eficiência e da estabilidade do sistema de tratamento anaeróbio, em dois estágios, estudado (Figura 2).

Confirma-se, então, a vantagem de usar sistemas de tratamento anaeróbio em dois estágios, nos quais o segundo reator contribui para a elevação e a manutenção da estabilidade das eficiências de remoção das frações solúveis e de sólidos suspensos, conforme também foi observado por SANTANA \& OLIVEIRA (2005) e FERNANDES \& OLIVEIRA (2006), com valores de 87 a $95 \%$ e de 84 a $96 \%$ para DQO total $_{\text {e }}$ SSV, respectivamente. 
As maiores produções volumétricas de metano no reator $\mathrm{ABR}$, de 0,144 e $0,154 \mathrm{~m}^{3} \mathrm{CH}_{4}$ $\left(\mathrm{m}^{3} \text { reator } \mathrm{d}\right)^{-1}$, ocorreram nos ensaios 1 e 2 , respectivamente, e diferiram significativamente $(\mathrm{P}<0,01)$ do $3^{-}$ensaio. No reator UASB, as maiores produções volumétricas de metano de $0,201 \mathrm{e}$ $0,227 \mathrm{~m}^{3} \mathrm{CH}_{4}\left(\mathrm{~m}^{3} \text { reator d }\right)^{-1}$ ocorreram nos ensaios 2 e 3 e diferiram significativamente $(\mathrm{P}<0,01)$ do ensaio 1 (Tabela 2). Isso ocorreu em virtude das maiores COV (de 13,29 e 10,58 g DQO total $(\mathrm{L} \mathrm{d})^{-1}$ ) aplicadas no reator UASB, nos ensaios 2 e 3 . Os valores da produção volumétrica de metano foram baixos comparando-se com os valores obtidos em reatores UASB, em dois estágios (RAMIRES, 2005; SANTANA \& OLIVEIRA, 2005), e reatores anaeróbios operados em batelada sequencial, em dois estágios (DUDA, 2006), tratando águas residuárias de suinocultura em condições similares de COV, em virtude da ausência de separação de fases eficiente no reator ABR.

SHE et al. (2006) operaram dois reatores ABR (90 L) com quatro câmaras, alimentados com sacarose, com DQO entre 1.500 e $3.000 \mathrm{mg} \mathrm{L}^{-1}$ e TDH entre 16 e $30 \mathrm{~h}$, e observaram que a produção de biogás aumentou de 1,27 para $4,46 \mathrm{~L}(\mathrm{~L} \mathrm{~d})^{-1}$, com o aumento da COV de 2,15 para $6,29 \mathrm{~kg}$ DQO $\left(\mathrm{m}^{3} \mathrm{~d}\right)^{-1}$. O conteúdo de metano no biogás variou entre 59 e $73 \%$ durante o experimento.

TABELA 4. Valores médios das concentrações (em $\mathrm{mg} \mathrm{L}^{-1}$ ) e coeficientes de variação (C.V.) de NTK, Ptotal, $\mathrm{K}, \mathrm{Ca}, \mathrm{Mg}, \mathrm{Cu}, \mathrm{Fe}, \mathrm{Mn}, \mathrm{Zn}$ e Na do afluente e efluentes dos reatores ABR e UASB. Concentration mean values (in $\mathrm{mg}^{-1}$ ) and variation coefficients (C.V.) of TKN, total-P, $\mathrm{K}, \mathrm{Ca}, \mathrm{Mg}, \mathrm{Cu}, \mathrm{Fe}, \mathrm{Mn}$, and $\mathrm{Zn}$ in the affluent and effluent of $\mathrm{ABR}$ and UASB reactors.

\begin{tabular}{|c|c|c|c|c|c|c|}
\hline \multirow{2}{*}{ Parâmetros } & \multirow{2}{*}{ Reator } & \multicolumn{3}{|c|}{ Ensaio } & \multirow{2}{*}{ C.V. (\%) } & \multirow{2}{*}{ Teste F } \\
\hline & & 1 & 2 & 3 & & \\
\hline \multirow{3}{*}{ NTK } & Afluente & $1.157 \mathrm{a}$ & $1.041 \mathrm{a}$ & $496 \mathrm{~b}$ & 41,0 & $6,42 * *$ \\
\hline & ABR & $360 \mathrm{ab}$ & $438 \mathrm{a}$ & $248 \mathrm{~b}$ & 34,0 & $4,55 *$ \\
\hline & UASB & $344 \mathrm{ab}$ & $466 \mathrm{a}$ & $250 \mathrm{~b}$ & 32,3 & $6,28 * *$ \\
\hline \multirow{3}{*}{ P-total } & Afluente & $781,7 \mathrm{a}$ & $571,0 \mathrm{ab}$ & $328,8 \mathrm{~b}$ & 40,7 & $6,91 * *$ \\
\hline & ABR & $303,2 \mathrm{ab}$ & $366,7 \mathrm{a}$ & $226,0 \mathrm{~b}$ & 33,1 & $3,55 *$ \\
\hline & UASB & $288,3 \mathrm{ab}$ & $400,3 \mathrm{a}$ & $214,1 \mathrm{~b}$ & 40,0 & $3,87 *$ \\
\hline \multirow{3}{*}{ K } & Afluente & $165,28 \mathrm{a}$ & $206,87 \mathrm{a}$ & $112,56 \mathrm{a}$ & 54,0 & $2,05 \mathrm{~ns}$ \\
\hline & ABR & $104,97 \mathrm{~b}$ & $226,78 \mathrm{a}$ & $93,61 \mathrm{~b}$ & 60,2 & $5,24 *$ \\
\hline & UASB & $105,24 \mathrm{a}$ & $249,09 \mathrm{a}$ & $97,55 \mathrm{a}$ & 81,2 & $3,20 \mathrm{~ns}$ \\
\hline \multirow{3}{*}{$\mathrm{Ca}$} & Afluente & $1.061,19 \mathrm{a}$ & $848,41 \mathrm{ab}$ & $499,80 \mathrm{~b}$ & 45,8 & $4,16^{*}$ \\
\hline & ABR & $193,56 \mathrm{~b}$ & $408,22 \mathrm{a}$ & $141,66 \mathrm{~b}$ & 60,4 & $6,23 * *$ \\
\hline & UASB & $164,89 \mathrm{~b}$ & $479,61 \mathrm{a}$ & $120,55 \mathrm{~b}$ & 86,3 & $5,07 *$ \\
\hline \multirow{3}{*}{$\mathrm{Mg}$} & Afluente & $80,71 \mathrm{a}$ & $34,91 \mathrm{~b}$ & $25,03 \mathrm{~b}$ & 39,4 & $18,13 * *$ \\
\hline & ABR & $37,64 \mathrm{a}$ & $32,84 \mathrm{ab}$ & $20,54 \mathrm{~b}$ & 35,5 & $4,70 *$ \\
\hline & UASB & $33,37 \mathrm{a}$ & $33,59 \mathrm{a}$ & $20,24 \mathrm{a}$ & 35,8 & $3,30 \mathrm{~ns}$ \\
\hline \multirow{3}{*}{$\mathrm{Cu}$} & Afluente & $2,50 \mathrm{a}$ & $11,44 \mathrm{a}$ & $2,01 \mathrm{a}$ & 140,6 & $3,53 *$ \\
\hline & ABR & $0,22 \mathrm{a}$ & $2,98 \mathrm{a}$ & 0,36 a & 157,9 & $4,05 *$ \\
\hline & UASB & $0,27 \mathrm{a}$ & $4,81 \mathrm{a}$ & $0,29 \mathrm{a}$ & 202,6 & $2,56 \mathrm{~ns}$ \\
\hline \multirow{3}{*}{$\mathrm{Fe}$} & Afluente & $47,83 \mathrm{a}$ & $49,29 \mathrm{a}$ & $18,17 \mathrm{~b}$ & 47,0 & $6,62 * *$ \\
\hline & $\mathrm{ABR}$ & $6,69 \mathrm{ab}$ & $13,31 \mathrm{a}$ & $3,83 \mathrm{~b}$ & 86,0 & $3,54 *$ \\
\hline & UASB & $3,72 \mathrm{~b}$ & $26,4 \mathrm{a}$ & $2,21 \mathrm{~b}$ & 143,5 & $4,82 *$ \\
\hline \multirow{3}{*}{$\mathrm{Mn}$} & Afluente & $4,30 \mathrm{ab}$ & $6,24 a$ & $2,16 \mathrm{~b}$ & 70,2 & $3,31 \mathrm{~ns}$ \\
\hline & ABR & $0,65 \mathrm{~b}$ & $2,14 \mathrm{a}$ & $0,80 \mathrm{~b}$ & 68,6 & $6,98 * *$ \\
\hline & UASB & $0,51 \mathrm{~b}$ & $2,89 \mathrm{a}$ & $0,64 \mathrm{~b}$ & 86,2 & $8,66 * *$ \\
\hline \multirow{3}{*}{$\mathrm{Zn}$} & Afluente & $12,60 \mathrm{a}$ & $18,39 \mathrm{a}$ & $8,71 \mathrm{a}$ & 65,5 & $2,20 \mathrm{~ns}$ \\
\hline & ABR & $0,46 \mathrm{~b}$ & $4,74 \mathrm{a}$ & $1,26 \mathrm{ab}$ & 109,5 & $5,09 *$ \\
\hline & UASB & $0,66 \mathrm{a}$ & $8,11 \mathrm{a}$ & $1,19 \mathrm{a}$ & 137,2 & $3,12 \mathrm{~ns}$ \\
\hline \multirow{3}{*}{$\mathrm{Na}$} & Afluente & $64,57 \mathrm{a}$ & $75,26 \mathrm{a}$ & $60,57 \mathrm{a}$ & 63,3 & $0,23 \mathrm{~ns}$ \\
\hline & ABR & $47,81 \mathrm{a}$ & $104,62 \mathrm{a}$ & $56,31 \mathrm{a}$ & 60,4 & $3,73 *$ \\
\hline & UASB & $49,26 \mathrm{a}$ & 109,89 a & $61,52 \mathrm{a}$ & 75,0 & $2,30 \mathrm{~ns}$ \\
\hline
\end{tabular}

Letras minúsculas diferentes na mesma linha, as médias diferem, pelo teste de Tukey, a 5\% de probabilidade. ** - significativo a $1 \%$ de probabilidade; $*$ - significativo a $5 \%$ de probabilidade; ns - não significativo. 
Verificou-se, também, que, conforme diminuiu o TDH, a produção de metano se deslocou do $1^{\circ}$ para o $2^{-}$reator (Tabela 2 e Figura 3 ). Isso porque, com o menor TDH, houve menos tempo para que, após a hidrólise e acidogênese, as arquéias metanogênicas transformassem os ácidos graxos voláteis produzidos em metano ainda no $1^{\underline{0}}$ estágio (reator $A B R$ ). Os valores de produção volumétrica de metano no sistema de tratamento (ABR+UASB) correlacionaram-se com as COV aplicadas nos reatores ABR e UASB, e os maiores valores $(\mathrm{P}<0,01)$ ocorreram no ensaio 2.

Os maiores valores de NTK, Fe e Mn no afluente ocorreram nos ensaios 1 e 2, com concentrações médias de 1.157 e $1.041 ; 47,83$ e 49,29; e 4,30 e 6,24 $\mathrm{mg} \mathrm{L}^{-1}$, respectivamente, acompanhando a variação de SST do afluente e também diferiram significativamente $(\mathrm{P}<0,05)$ do ensaio 3 (Tabela 4). A maior eficiência de remoção de NTK no sistema de tratamento (ABR+UASB), de $71 \%$, ocorreu no $1^{\circ}$ ensaio e não diferiu significativamente do valor de $51 \%$ obtido no $2^{\underline{o}}$ ensaio (Tabela 5 ).

Os valores de P-total, $\mathrm{Ca}$ e $\mathrm{Mg}$ no afluente variaram de 328,8 a 781,7; 499,80 a $1.061,19$ e 25,03 a $80,71 \mathrm{mg} \mathrm{L}^{-1}$, respectivamente, com diferenças significativas $(\mathrm{P}<0,05)$ entre os ensaios 1 e 3 (Tabela 4). Pelo efeito do maior TDH, no ensaio 1, como ocorreu para o NTK, obtiveram-se as maiores (P>0,01) eficiências de remoção de P-total, $\mathrm{Mg}, \mathrm{Mn}$ e $\mathrm{Zn}$, as quais foram de 61; 58; 85 e 95\% no sistema de tratamento anaeróbio, em dois estágios (Tabela 5). A maior parte da remoção de NTK, P-total, K, Ca, Mg, Cu, Fe, Mn e Zn ocorreu no reator ABR.

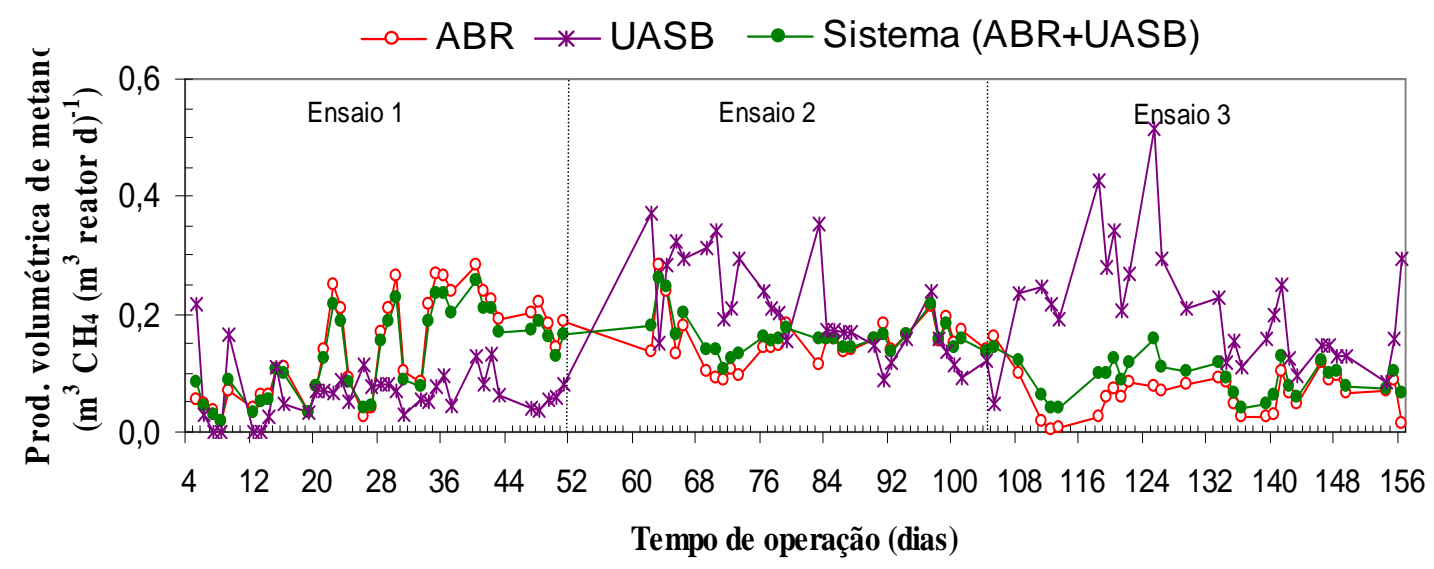

FIGURA 3. Valores da produção volumétrica de metano no reator ABR e UASB e no sistema de tratamento anaeróbio, em dois estágios (ABR+UASB), nos ensaios 1; 2 e 3. Values of volumetric methane production in the ABR and UASB reactors and in the twostage anaerobic treatment system (ABR + UASB), in tests 1; 2 and 3.

Os valores de eficiência de remoção de alguns nutrientes são discrepantes em relação às concentrações apresentadas na Tabela 4, em virtude da ausência de remoção dos mesmos em algumas amostragens. As médias apresentadas na Tabela 5 são provenientes das amostragens nas quais houve remoção.

Em trabalhos realizados por DUDA (2006) e RAMIRES (2005), tratando águas residuárias de suinocultura com SST em torno de $10.000 \mathrm{mg} \mathrm{L}^{-1}$, em dois reatores sequenciais em batelada anaeróbios e dois reatores UASB em série, com TDH de 36 a 96 h e de 18 e 36 h, no $1^{\circ}$ reator, e $\mathrm{COV}$ de 4,43 a 12,75 e de 5,5 a $13,2 \mathrm{~g} \mathrm{DQO}_{\text {total }}\left(\mathrm{L} \mathrm{d}^{-1}\right.$, respectivamente, verificaram-se remoções máximas para NTK, P-total, Fe, Zn, Cu, Mn, Ca, Mg e Na de 68,9; 74,5; 93,7; 76,4; 88,6; 69,7; 61,$7 ; 33,1$ e $8,9 \%$. As eficiências de remoção verificadas neste trabalho, com os reatores ABR e UASB, no ensaio 1, foram superiores aos valores obtidos por DUDA (2006) e similares aos obtidos por RAMIRES (2005), mesmo aplicando-se TDH menor ou semelhante, indicando a melhor retenção de sólidos no lodo, no sistema de tratamento (ABR+UASB), mecanismo pelo qual 
predomina a remoção dos nutrientes. Além de necessários ao processo anaeróbio, os nutrientes presentes no efluente e retidos no lodo dos reatores podem ser aplicados em doses controladas como fertilizantes e, ao mesmo tempo, evitar poluição.

TABELA 5. Valores das eficiências de remoção (\%) e coeficientes de variação (CV) de NTK, Ptotal, $\mathrm{K}, \mathrm{Ca}, \mathrm{Mg}, \mathrm{Cu}, \mathrm{Fe}, \mathrm{Mn}, \mathrm{Zn}$ e Na nos efluentes do reator ABR, UASB e para o sistema de tratamento anaeróbio, em dois estágios (ABR+UASB), nos ensaios 1; 2 e 3. Values of the removal efficiencies $(\%)$ and variation coefficients $(\mathrm{CV})$ of $\mathrm{TKN}$, total-P, K, Ca, Mg, $\mathrm{Cu}, \mathrm{Fe}, \mathrm{Mn}, \mathrm{Zn}$ and $\mathrm{Na}$ in the effluent of ABR and UASB reactors, and for two-stage anaerobic treatment system (ABR + UASB) in tests 1; 2 and 3.

\begin{tabular}{|c|c|c|c|c|c|c|}
\hline \multirow{2}{*}{ Parâmetros } & \multirow{2}{*}{ Reator } & \multicolumn{3}{|c|}{ Ensaio } & \multirow{2}{*}{ C.V. $(\%)$} & \multirow{2}{*}{ Teste F } \\
\hline & & 1 & 2 & 3 & & \\
\hline \multirow{3}{*}{ NTK } & ABR & $69 \mathrm{a}$ & $52 \mathrm{ab}$ & $47 \mathrm{~b}$ & 27,5 & $3,92 *$ \\
\hline & UASB & 7 & - & - & - & - \\
\hline & Sistema & $71 \mathrm{a}$ & $51 \mathrm{ab}$ & $46 \mathrm{~b}$ & 26,1 & $5,32 *$ \\
\hline \multirow{3}{*}{ P-total } & ABR & $59 a$ & $41 \mathrm{~b}$ & $29 \mathrm{~b}$ & 29,0 & $10,61 * *$ \\
\hline & UASB & $7 \mathrm{a}$ & - & $9 \mathrm{a}$ & 89,0 & $0,06 \mathrm{~ns}$ \\
\hline & Sistema & $61 \mathrm{a}$ & $39 \mathrm{~b}$ & $30 \mathrm{~b}$ & 34,1 & $7,55 * *$ \\
\hline \multirow{3}{*}{ K } & ABR & $38 \mathrm{a}$ & $19 \mathrm{a}$ & $19 \mathrm{a}$ & 58,9 & $2,89 \mathrm{~ns}$ \\
\hline & UASB & - & - & - & - & - \\
\hline & Sistema & $38 \mathrm{a}$ & - & $19 \mathrm{a}$ & 50,5 & $3,77 \mathrm{~ns}$ \\
\hline \multirow{3}{*}{$\mathrm{Ca}$} & ABR & $78 \mathrm{a}$ & $55 \mathrm{a}$ & $65 \mathrm{a}$ & 30,6 & $2,16 \mathrm{~ns}$ \\
\hline & UASB & $18 \mathrm{~b}$ & - & $54 \mathrm{a}$ & 59,0 & $7,14 *$ \\
\hline & Sistema & $80 \mathrm{a}$ & $50 \mathrm{a}$ & $63 \mathrm{a}$ & 40,9 & $2,12 \mathrm{~ns}$ \\
\hline \multirow{3}{*}{$\mathrm{Mg}$} & $\mathrm{ABR}$ & $51 \mathrm{a}$ & $14 \mathrm{~b}$ & $20 \mathrm{~b}$ & 48,4 & $12,5 * *$ \\
\hline & UASB & $15 \mathrm{~b}$ & - & $39 a$ & 55,3 & $6,47 *$ \\
\hline & Sistema & $58 \mathrm{a}$ & $14 \mathrm{~b}$ & $42 \mathrm{a}$ & 26,7 & $30,1 * *$ \\
\hline \multirow{3}{*}{$\mathrm{Cu}$} & ABR & $91 \mathrm{a}$ & $87 \mathrm{a}$ & $78 \mathrm{a}$ & 11,8 & $2,60 \mathrm{~ns}$ \\
\hline & UASB & - & - & 28 & - & - \\
\hline & Sistema & $89 a$ & $73 \mathrm{a}$ & $75 \mathrm{a}$ & 20,2 & $1,55 \mathrm{~ns}$ \\
\hline \multirow{3}{*}{$\mathrm{Fe}$} & ABR & $85 \mathrm{a}$ & $81 \mathrm{a}$ & $77 \mathrm{a}$ & 11,2 & $1,51 \mathrm{~ns}$ \\
\hline & UASB & $53 a$ & - & $33 \mathrm{~b}$ & 32,8 & $6,42 *$ \\
\hline & Sistema & $91 \mathrm{a}$ & $68 \mathrm{a}$ & $85 \mathrm{a}$ & 19,0 & $3,20 \mathrm{~ns}$ \\
\hline \multirow{3}{*}{$\mathrm{Mn}$} & $\mathrm{ABR}$ & $81 \mathrm{a}$ & $71 \mathrm{ab}$ & $59 \mathrm{~b}$ & 16,7 & $6,06 *$ \\
\hline & UASB & $28 \mathrm{a}$ & - & $18 \mathrm{a}$ & 43,7 & $2,37 \mathrm{~ns}$ \\
\hline & Sistema & $85 \mathrm{a}$ & $62 \mathrm{~b}$ & $64 \mathrm{~b}$ & 16,1 & $8,34 * *$ \\
\hline \multirow{3}{*}{$\mathrm{Zn}$} & ABR & $96 \mathrm{a}$ & $79 \mathrm{~b}$ & $82 \mathrm{~b}$ & 10,0 & $6,11 *$ \\
\hline & UASB & - & - & 24 & - & - \\
\hline & Sistema & $95 \mathrm{a}$ & $66 \mathrm{~b}$ & $84 \mathrm{a}$ & 13,6 & $8,38 * *$ \\
\hline \multirow{3}{*}{$\mathrm{Na}$} & $\mathrm{ABR}$ & $36 a$ & - & $11 \mathrm{~b}$ & 63,0 & $9,01 *$ \\
\hline & UASB & - & - & - & - & - \\
\hline & Sistema & 33 & - & - & - & - \\
\hline
\end{tabular}

Letras minúsculas diferentes na mesma linha, as médias diferem, pelo teste de Tukey, a 5\% de probabilidade. ** - significativo a $1 \%$ de probabilidade; * - significativo a $5 \%$ de probabilidade; ns - não significativo.

Em relação à remoção de coliformes totais e termotolerantes, o reator $A B R$ foi o mais eficiente com remoções de até $99,59 \%$ no ensaio 1 , enquanto no reator UASB, as maiores eficiências ocorreram nos ensaios 2 e 3, com valores de até 53,76\% (Tabela 6). 
TABELA 6. Valores médios de número mais provável (NMP) de coliformes totais e termotolerantes nos afluentes e efluentes, e eficiências de remoção no reator compartimentado, UASB, e sistema de tratamento anaeróbio, em dois estágios (ABR+UASB), nos ensaios 1; 2 e 3. Values of most probable number (MPN) of total and thermotolerant coliforms in affluents and effluents and removal efficiencies of the anaerobic baffled reactor, UASB and two-stage anaerobic treatment system $(A B R+$ UASB $)$ in tests $1 ; 2$ and 3.

\begin{tabular}{|c|c|c|c|c|c|}
\hline \multirow{2}{*}{ Ensaio } & \multirow{2}{*}{ Local de Amostragem } & \multicolumn{2}{|c|}{ Coliformes Totais } & \multicolumn{2}{|c|}{ Coliformes Termotolerantes } \\
\hline & & $\mathrm{NMP} / 100 \mathrm{~mL}$ & $\%$ de Remoção & NMP/100 mL & \% de Remoção \\
\hline \multirow{4}{*}{1} & Afluente & $5,4 \quad 10^{7}$ & & $4,310^{7}$ & \\
\hline & ABR & $2,2 \quad 10^{5}$ & 99,59 & $1,9 \quad 10^{5}$ & 99,56 \\
\hline & UASB & $1,8 \quad 10^{5}$ & 18,18 & $1,510^{5}$ & 21,05 \\
\hline & Sistema & & 99,67 & & 99,65 \\
\hline \multirow{4}{*}{2} & Afluente & $7,5 \quad 10^{6}$ & & $5,510^{6}$ & \\
\hline & ABR & $9,310^{5}$ & 87,60 & $7,310^{5}$ & 86,73 \\
\hline & UASB & $4,3 \quad 10^{5}$ & 53,76 & $3,3 \quad 10^{5}$ & 54,79 \\
\hline & Sistema & & 94,27 & & 94,00 \\
\hline \multirow{4}{*}{3} & Afluente & $2,310^{7}$ & & $1,810^{7}$ & \\
\hline & ABR & $3,210^{6}$ & 86,09 & $2,210^{6}$ & 87,78 \\
\hline & UASB & $1,8 \quad 10^{6}$ & 43,75 & $1,3 \quad 10^{6}$ & 40,91 \\
\hline & Sistema & & 92,17 & & 92,78 \\
\hline
\end{tabular}

Mesmo alcançando eficiências de até $99,67 \%$ de remoção no sistema de tratamento anaeróbio em dois estágios, as concentrações de coliformes permaneceram acima de $10^{5} \mathrm{NMP} / 100 \mathrm{~mL}$, e assim ainda não foi possível atingir valores que permitam a utilização do efluente tratado na irrigação, de acordo com referências na legislação brasileira (BRASIL, 2005) e nas diretrizes da Organização Mundial de Saúde (WHO, 2006).

As eficiências de remoção de $\mathrm{DQO}_{\text {total }}$ e de $\mathrm{DQO}_{\mathrm{ss}}$ no reator UASB; de $\mathrm{DQO}_{\text {diss }}$, NTK, P-total, $\mathrm{Mg}, \mathrm{Mn}$ e $\mathrm{Zn}$ no reator ABR e no sistema de tratamento (ABR+UASB); e de SST e SSV nos reatores ABR e UASB e no sistema de tratamento (ABR+UASB) apresentaram diferenças significativas com os maiores valores coincidindo com a ocorrência da temperatura média do ar e do TDH mais altos $\left(24,6^{\circ} \mathrm{C}\right.$ e 60 horas, respectivamente). O mesmo ocorreu com as eficiências de remoções dos coliformes totais e termotolerantes no sistema de tratamento (ABR+UASB). O aumento da temperatura e do TDH otimizam a atividade dos microrganismos anaeróbios e o tempo de contato com o substrato, além da sedimentação dos sólidos suspensos na manta de lodo, influenciando a eficiência de remoção no sistema de tratamento (ABR+UASB).

\section{CONCLUSÕES}

O sistema de tratamento anaeróbio, em dois estágios, com reatores ABR e UASB, foi eficiente nas remoções de DQO, sólidos suspensos e coliformes, possibilitando, nas condições operacionais impostas, alcançar valores médios acima de $85 \%$. Para a remoção de nutrientes (NTK, P-total, $\mathrm{Ca}, \mathrm{Cu}, \mathrm{Fe}, \mathrm{Mn}$ e $\mathrm{Zn}$ ), foi possível obter valores máximos predominantemente superiores a $60 \%$. As eficiências de remoção de matéria orgânica e nutrientes aumentaram conforme se aumentou o tempo de detenção hidráulica (TDH).

A maior parte da remoção de matéria orgânica, sólidos suspensos, macro e micronutrientes e coliformes ocorreu no reator ABR, por meio de remoção física.

A utilização do reator UASB, instalado em série, foi importante para manter as eficiências de remoção do sistema de tratamento estáveis. 
Os valores de COV de 11,51 a 17,98 $\mathrm{g} \mathrm{DQO}_{\text {total }}(\mathrm{L} \mathrm{d})^{-1}$, aplicados no reator ABR, não foram limitantes para a obtenção de altas eficiências de remoção de DQO e sólidos suspensos, na faixa de 69 a 92\%, indicando que o mesmo ainda pode suportar maior COV e/ou menor TDH.

Para as remoções de DQO e produção de metano, no sistema de tratamento anaeróbio em dois estágios, com os reatores ABR e UASB, com TDH de 44,2 e 29,4 h, foi possível obter valores similares ou superiores e com maior estabilidade do que os obtidos com o reator ABR com TDH de $60 \mathrm{~h}$. Assim, o melhor desempenho do processo anaeróbio, em dois estágios, pode ser obtido com até metade do volume de reatores em relação ao reator em único estágio, indicando economia significativa na implantação de estações de tratamento de águas residuárias de suinocultura.

\section{AGRADECIMENTOS}

À FAPESP, à CAPES e a TIGRE S.A. Tubos e conexões, pelo apoio financeiro.

\section{REFERÊNCIAS}

APHA/AWWA/WPCF. Standard methods for the examination of water and wastewater. $20^{\text {th }}$, Washington, 1998. $1.569 \mathrm{p}$.

BARBER, W.P.; STUCKEY, D.C. The use of anaerobic baffled reactor (ABR) for the wastewater treatment: a review. Water Research, Oxford, v.33, n.7, p.1.559-1.578, 1999.

BRASIL. RESOLUÇÃO CONAMA ñ 357/2005 - "Dispõe sobre a classificação dos corpos de água e diretrizes ambientais para o seu enquadramento, bem como estabelece as condições e padrões de lançamento de efluentes, e dá outras providências." - Data da aprovação: 17-3-2005 Publicação DOU n ${ }^{o}$ 053, de 18-3-2005, p.58-63.

CHERNICHARO, C.A.L. Reatores anaeróbios: princípios do tratamento biológico em águas residuárias. 2.ed. Belo Horizonte: DESA/UFMG, 2007. 359 p.

DILALLO, R.; ALBERTSON, O.E. Volatile acids by direct titration. Journal Water Pollution Control Federation, Alexandria, v.33, n.4, p.356-365, 1961.

DUDA, R.M. Desempenho de reatores sequenciais em batelada anaeróbios em dois estágios seguidos de lagoas de polimento em série para o tratamento de águas residuárias de suinocultura. 2006. 146 f. Dissertação (Mestrado em Microbiologia Agropecuária) - Faculdade de Ciências Agrárias e Veterinárias, Universidade Estadual Paulista, Jaboticabal, 2006.

FERNANDES, G.F.R. Desempenho de processo anaeróbio em dois estágios (reator compartimentado seguido de reator UASB) para tratamento de águas residuárias de suinocultura. 2004. 136 f. Dissertação (Mestrado em Microbiologia Agropecuária) - Faculdade de Ciências Agrárias e Veterinárias, Universidade Estadual Paulista, Jaboticabal, 2004.

FERNANDES, G.F.R.; OLIVEIRA, R.A. de. Desempenho de processo anaeróbio em dois estágios (reator compartimentado seguido de reator UASB) para tratamento de águas residuárias de suinocultura. Engenharia Agrícola, Jaboticabal, v.26, n.1, p.243-256, 2006.

HAANDEL, A.C. Van.; LETTINGA, G. Anaerobic sewage treatment: a pratical guide for regions with a hot climate. Chichester: John Wiley, 1994. 226 p.

JENKINS, S.R.; MORGAN, J.M.; SAWYER, C.L. Measuring anaerobic sludge digestion and growth by a simple alkalimetric titration. Journal Water Pollution Control Federal, Alexandria, v.55, n.5, p.448-453, 1983.

LANGENHOFF, A.A.M.; STUCKEY, D.C. Treatment of dilute wastewater using an anaerobic baffled reactor: effect of low temperature. Water Research, Oxford, v.34, n.15, p.3.867-3.875, 2000.

LETTINGA, G. Anaerobic digestion and wastewater treatment systems. Antonie van Leeuwenhoek, Dordrecht, v.67, n.1, p.3-28, 1995. 
NACHAIYASIT, S.; STUCKEY, D.C. The effect of shock loads on the performance of an anaerobic baffled reactor (ABR). 1. Step changes in feed concentration at constant retention time. Water Research, Oxford, v.31, n.11, p.2.737-2.746, 1997.

OLIVEIRA, R.A. de. Efeito da concentração de sólidos suspensos do afluente no desempenho e características do lodo de reatores anaeróbios de fluxo ascendente com manta de lodo tratando águas residuárias de suinocultura. 1997. 359 f. Tese (Doutorado em Hidráulica e Saneamento) Escola de Engenharia, Universidade de São Paulo, São Carlos, 1997.

RAMIRES, R.D.A. Produção de metano e remoção de matéria orgânica, nutrientes e microrganismos patogênicos em reatores anaeróbios de fluxo ascendente com manta de lodo (UASB) em dois estágios tratando águas residuárias de suinocultura. 2005. 136 f. Dissertação (Mestrado em Microbiologia Agropecuária) - Faculdade de Ciências Agrárias e Veterinárias, Universidade Estadual Paulista, Jaboticabal, 2005.

SANTANA, A.M. da; OLIVEIRA, R.A. de. Desempenho de reatores anaeróbios de fluxo ascendente com manta de lodo em dois estágios tratando águas residuárias de suinocultura. Engenharia Agrícola, Jaboticabal, v.25, n.3, p.817-830, 2005.

SHE, Z.; ZHENG, X.; YANG, B.; JIN, C.; GAO, M. Granule development and performance in sucrose fed anaerobic baffled reactors. Journal of Biotechnology, Amsterdam, v.122, p.198-208, 2006.

SILVA, G.H.R.; NOUR, E.A.A. Reator compartimentado anaeróbio/aeróbio: sistema de baixo custo para tratamento de esgotos de pequenas comunidades. Revista Brasileira de Engenharia Agrícola e Ambiental, Campina Grande, v.9, n.2, p. 268-275, 2005.

VOSSOUGHI, M.; SHAKERI, M.; ALEMZADEH, I. Performance of anaerobic baffled reactor treating synthetic wastewater influenced by decreasing $\mathrm{COD} / \mathrm{SO}_{4}$ ratios. Chemical Engineering and Processing, Tehran, v.42, n.10, p.811-816, 2003.

WHO. WORLD HEALTH ORGANIZATION. Guidelines for the safe use of wastewater, excreta and greywater. Geneva, 2006. 4v. Disponível em: <http://www.who.int/ water_sanitation_ healthwastewater/gsuww/en/index.html>. Acesso em: 27 out. 2008. 